\title{
Introduction to eSourcing of Business Processes and Software Products and Services Minitrack
}

\author{
Timo Käkölä \\ University of Jyväskylä \\ timokk66@gmail.com
}

\author{
Bill Hefley \\ University of Texas at Dallas \\ william.hefley@utdallas.edu
}

This minitrack is interested in contributions that help providers and customers to enhance their eSourcing maturity from simple cost-driven engagements to strategic partnerships bringing significant and sustained value. The minitrack welcomes, but is not limited to, contributions in the following areas:

- The design, adaptation, implementation, and/or validation of process reference models for the eSourcing life-cycle

- The design, adaptation, implementation, and/or validation of process assessment models for the eSourcing life-cycle

- The design, adaptation, implementation, and/or validation of new strategic initiatives such as platform-based BPO (PaaS), enabling masscustomized, high-margin services

- New pricing models in eSourcing such as valuebased, outcome-based (e.g., price per software function point), pay per use, and risk/reward models

- In depth investigation of eSourcing reference models, process assessment models, and enabling information systems in different industry verticals such as logistics, manufacturing, and health care

- Innovation and supplier-relationship management to support innovative eSourcing engagements

- Tools and technology to support eSourcing 